\title{
5 Research Square

\section{One-day combined botulinum toxin injections and pulsed radiofrequency of greater occipital nerve for treatment refractory chronic migraine}

Alexey Voloshin ( $\sim$ voloshin.icu@gmail.com )

CELT https://orcid.org/0000-0001-5821-4296

I.V. Moiseeva

CELT

\section{Research article}

Keywords: refractory chronic migraine, GON pulsed radiofrequency, botulinum toxin injections, interventional pain treatment, combined interventional procedures

Posted Date: September 9th, 2020

DOI: https://doi.org/10.21203/rs.3.rs-66136/v1

License: (c) (i) This work is licensed under a Creative Commons Attribution 4.0 International License.

Read Full License 


\section{Abstract}

Background. The aim of this study was to evaluate the potential of combined the greater occipital nerve's (GON) pulsed radiofrequency (PRF) with botulinum toxin therapy procedures for treatment the refractory chronic migraine.

Methods. We had 6 patients, all female, from 33 to 57 years old suffering from refractory chronic migraine (RCM) according to the European Headache proposed criteria. All patients had migraine from 5 to 44 years and refractory migraine from 1 to 10 years. Simultaneous one-day treatments were undertaken: first step - botulinum toxin type A injections in accordance with the PREEMPT protocol. Second step - the PRF stimulation on the bilateral GONs was performed under the guidance of ultrasound. The follow-up duration after the procedure was 6 months.

Results. We had a positive response to treatment from all patients. As a result, we observed a dramatic reduction of pain intensity from $7 \pm 1$ to $2 \pm 2$ on NRS scale and, most importantly, a significant decrease in the number of days with headache from $22 \pm 5$ to $4 \pm 4$ during first month after treatment, with two patients (30\% of patients) recording a complete regression of migraine attacks. None of the patients had any adverse effects.

Conclusion. The simultaneous one-day use of PRF GON with botulinum toxin therapy may be a useful option for the treatment of refractory chronic migraine. The combined interventional procedures are effective, minimally invasive, inexpensive, safe, well tolerated and can be performed on an outpatient basis.

\section{Introduction}

Clinical practice considers migraine as the most common neurological disease [1]. As Global Burden of Disease 2016 illustrates, migraine is one of the main causes of disability globally. Chronic migraine is a subclass of migraine, it prevails in $8 \%$ among migraineurs and about $2 \%$ of the general population [2]. Chronic migraine substantially deteriorates the patients' quality of life due to at least 15 headache days per month (8 out of 15 days with migraine with or without aura) they have for at least three consecutive months [3].

Some individuals suffering from migraine are resistant to guideline-based treatment despite substantial advances in migraine therapy [4]. Approximately $4 \%$ of the world's population are exposed to refractory chronic migraine (RCM) resulting in severe pain, lifestyle limitations, and deterioration in life quality. The quality and quantity of an individual's work also deteriorates resulting in significant economic losses. RCM is still one of the hardest challenges in headache medicine [5,6]. In the US-headache clinic $5.1 \%$ of the migraine patients have been diagnosed with refractory migraine using the criteria proposed by RHSIS [7]. 
Botulinum toxin type $A$ is a protein that holds back the release of acetylcholine from presynaptic nerve endings and inhibits the release of calcitonin gene-related peptide and substance $P$. For chronic migraine there is only one agent which is approved. It is onabotulinumtoxin A (BTA). Currently, BoNT-A is approved for the prophylactic treatment of migraines in the USA, Australia, India, Brazil, Russia, Canada, and Korea [8]. Having received the results of the PREEMPT trials the efficacy of this treatment for chronic migraine was confirmed. The efficacy of OnabotA is proved by this study resulting in decreasing the frequency of headache days per month. It reduces the medication use and improves the quality of life. The PREEMPT trials also illustrated the treatment's safety and tolerability and the low incidence of associated side effects [9-11].

The pulsed radiofrequency (PRF) technique was initially described by Sluijter in 1997 (12). The method delivers an electrical field and heat bursts to targeted nerves or tissues without damaging these structures. As far as pain alleviation is concerned this procedure is known to be safe and effective (13). PRF applies a brief electrical stimulation with a long resting phase afterwards. In this case PRF does not produce sufficient heat which might cause structural damage (14). The proposed PRF mechanism implies that the electrical field produced by PRF can alter pain signals (15). PRF reportedly can effectively manage various types of headaches, including occipital neuralgia, cervicogenic headache, and intracranial hypotension headache, by applying it to the greater occipital nerve (GON) [16-18].

Objective The aim of this study was to evaluate the potential of combined one-day the GON PRF with botulinum toxin therapy procedures for treatment the RCM.

\section{Materials And Methods}

Patients. We had 6 patients, all female, from 33 to 57 years old suffering from refractory chronic migraine (RCM) according to the European Headache proposed criteria [19]. They also had contraindications or no effect of the preventive medication with at least 3 drugs. All patients had migraine from 5 to 44 years. RCM duration was from 1 to 10 years. Patient's demographic and pretreatment data are shown in table 1. Prior to the procedure, all patients were informed that the procedure was experimental and did not promise guaranteed benefits, and informed consents were obtained from each patient. RCM was diagnosed with no previous medication overuse.

Procedures. Simultaneous one-day treatment was undertaken: first step - botulinum toxin type A injections (Onabotulinum A, Botox ${ }^{\circledR}$, Allergan). We used the total dosage of 195 Units as in the PREEMPT trials. All patients were given injections at: two corrugators, one procerus, four frontalis, eight temporalis, six occipitalis sites. All of them received additional injections at 2 temporalis muscle, 2 occipitalis muscle and 4 in the trapezium according to the Follow-The-Pain method. The last botulinum toxin injections were given to each patient more than 6 months before our interventional treatment.

Second step - PRF stimulation on the bilateral GONs was performed under the guidance of ultrasound to manage the headache. The aseptic technique was applied during the PRF procedure. The patients were maintained in the prone position. We searched the GON using a 6 to $15 \mathrm{MHz}$ linear probe (LOGIQ P6, 
General Electric, Seoul, Korea) following the method by Greher et al [20]. We located the ultrasound probe on the spinous process of $\mathrm{C} 2$, and subsequently moved the probe laterally to identify the obliquus capitis inferior muscle of the neck. The GON was found superficial to the obliquus capitis inferior muscle at this level (Fig 1.) After identifying the GON, the catheter needle (22-gauge $5 \mathrm{~mm}$ active tip electrode) was inserted, and the sensory stimulation test was carried out using an RF generator (RFG4, Cosman Medical, Burlington, Massachusetts). Under ultrasound guidance, the catheter needles were placed close to the right and left GONs, and the patient indicated dysesthesia and a tingling sensation at the occipital area with less than $0,3 \mathrm{~V}$ (Fig 2.) The PRF treatment was administered at $5 \mathrm{~Hz}$ and 5 milliseconds pulsed width for 360 seconds at $65 \mathrm{~V}$ under the constraint that the temperature of the electrode tips did not exceed $42^{\circ} \mathrm{C}$ (Fig 3).

Patients remained in the hospital for at least 2 hours upon expiration of the control period, and in the absence of warning signs, they were discharged home.

\section{Outcome measures:}

The follow-up duration after the procedure was 6 months. During the research period our patients were monitored during their visits to the clinic. In case visits were not possible we followed up our patients by phone calls. Pretreatment means headache days, and pain attack intensity was measured with a 0-10 numeric rating scale (NRS), and compared to post-treatment values.

Statistical analysis was performed using StatPlus for Mac. Continuous variables are presented as mean \pm standard deviation (SD). Within the group, differences were verified using the Wilcoxon rank sum test. The level of statistical significance was $\mathrm{P}<0.05$.

\section{Results}

We had a positive response to treatment from all patients. As a result, we observed a dramatic reduction of pain intensity from $7 \pm 1$ to $2 \pm 2$ on NRS scale (Fig 4) and, most importantly, a significant decrease in the number of days with headache from $22 \pm 5$ to $4 \pm 4$ during first month after treatment, with two patients ( $30 \%$ of patients) recording a complete regression of migraine attacks (Fig 5). Effect one-day treatment lasted at least 6 months. In addition, some patients halved the dose of daily medication and noticed the appearance of the effect of abortive therapy of triptans and NSAIDs (Table 2.)

\section{Discussion}

The pathophysiology of migraine is complex and is still a focus of research. The main mechanisms of migraine are hypothalamic activation, alteration in thalamo-cortical circuits, altered brain connectivity, brainstem activation, cortical spreading depolarization, release of CGRP and PACAP [21]. 
A pool of analysis of the data from two programmes of Phase 3 Research Evaluating Migraine Prophylaxis Therapy (PREEMPT 1 and 2) [22] with BoNT-A in chronic migraine demonstrated significant benefit of BoNT-A over placebo with regard to the numbers of headache days and migraine episodes. However, the effectiveness of botulinum therapy in the treatment of refractory migraine leaves much to be desired. Thus, the effectiveness of botulinum therapy in the treatment of refractory chronic migraine is about $37-50 \%$ [23-25]. With the exception of the reasons associated with the diagnosis, dose of the drug and the execution of the procedure, the main problem may be low individual susceptibility and neutralizing antibodies $[26,27]$.

Cases of PRF GON have been described in two young women suffering from refractory migraine. They underwent botulinum therapy according to the PREEEMPT protocol at a dose of 155 units and at the same time a block of GON, then after a negative response, performed PRF GON with success in reducing pain intensity by twice for at least 3 months [28]. Another case of a young 34-year-old woman who suffered from a complex headache of the type of chronic migraine, autonomic cephalgia, and occipital neuralgia. She was treated PRF DRG C2 with excellent effect throughout the year [29]. Unfortunately, it is still unclear, whether she suffered mainly from migraines or whether the effectiveness of C2 RFA was associated with the successful treatment of occipital neuralgia.

An interesting question is whether it is possible to change PRF GON with a simpler and cheaper block of the GON, albeit performed repeatedly. There is evidence that a single injection of a local anesthetic can reduce the intensity of pain in chronic migraines, however, a low pain intensity in the study group should be noted - the decrease was from $3.93 \pm 1.8$ to $1.55 \pm 1.42 \mathrm{~mm}$ VAS, also in this the study did not indicate whether the effect of a single block on the number of pain attacks or days with a headache [30]. In a prospective multicenter study of 84 patients suffering from chronic migraine diagnosed according to the criteria of the IHS 2004 HCCC patients received 4 blocks of GON weekly. Researchers got a good effect in the form of reducing the number of days with a headache from 18 to 9 days a month, as well as reducing the intensity of pain during an attack. It is noteworthy that in the group of patients receiving placebo, there was also a decrease in the number of days with headache per month from 17 to 13, and a slight decrease in pain intensity. Nevertheless, it has been sufficiently convincingly proved that a series of GON blocks with bupivacaine effectively reduces the number of migraine attacks and the intensity of pain. As the study design was cross-sectional, and the treatment group patients received several more GON injections with bupivacaine, it is difficult to estimate how long-term this treatment is [31]. Attempts have been described to treat chronic migraine with chronic neuromodulation of the GON. In a study of 66 patients whose $\mathrm{CM}$ was diagnosed using the second edition of the ICHD-II. After a positive response to the test block of GON, the best result was obtained in the group with adjustable neuromodulation, the decrease in the number of days with a headache was $27 \%$. However, even such a good result, the best among the study groups still chronic migraine - the decrease was from $22.4 \pm 6.3$ days to $15.7 \pm 10.0$ days. The percentage of respondents - patients in whom the number of days with a headache decreased by $50 \%$ after stimulation in the best group by adaptive stimulation was 39\% [32]. 
The main hypothesis of our study is that botulinum toxin reduces peripheral nociceptive afferentation and interrupts the release of inflammatory neuropeptides in the trigeminal complex with a further decrease in neurogenic inflammation of the vessels of the dura mater, which affects the trigeminovascular complex, and PRF affects the non-myelinated (C-fibers) and thinly myelinated (Aסfibers) axons, participating in the suppression of cortical depolarization through the system of trigeminocervical complex. Therefore, we associate the effectiveness of joint interventional treatment with the simultaneous impact on two main centers of regulation of mechanisms that ensure the emergence and maintenance of neurogenic inflammation and cortical depression - the trigeminovascular and trigeminocervical systems.

Limitations. The main limitation of this study is the small sample size of heterogeneous patients, short follow-up period and the absence of a comparison group. We should note that our patients were exposed to two invasive procedures therefore it might result in some placebo response distortion. Also we wish we had a larger sample size to strengthen our conclusions.

\section{Conclusion}

The simultaneous one-day use of PRF GON with botulinum toxin therapy may be a useful option for the treatment of refractory chronic migraine. The combined interventional procedures are effective, minimally invasive, inexpensive, safe, well tolerated and can be performed on an outpatient basis.

\section{List Of Abbreviations}

BTA, BoNT-A - onabotulinumtoxin A

GON - greater occipital nerve

NRS - numeric rating scale

PRF - pulsed radiofrequency

RCM - refractory chronic migraine

\section{Declarations}

Ethics approval and consent to participate. This retrospective study protocol was approved by the local ethics committee of the Center of endosurgery and lithotripsy (CELT) Moscow, Russia in accordance with the Declaration of Helsinki.

Consent for publication. Informed written consent was provided from the patients for participation in this study and publication of these accompanying images. 
Availability of data and materials. The datasets generated during and/or analyzed during the current study are available from the corresponding author on reasonable request.

Competing interests. The authors declare that they have no competing interests.

Funding. No funding or sponsorship was received for this study. The Rapid Service Fee was funded by the M. Schilling GmbH, In den Kappeswiesen 18, D-63571 Gelnhausen-Hailer, Germany.

Authors' contributions. IM perfomed procedures, collected data and have drafted the work.

AV created the conception and design of the work, interpretation of data and substantively revised it. All authors read and approved the final manuscript.

Acknowledgements. We thank the participants of the study.

\section{References}

1. Steiner TJ, Birbeck GL, Jensen R, Katsarava Z, Martelletti P, Stovner LJ. The Global Campaign, World Health Organization and Lifting The Burden: collaboration in action. J Headache Pain. 2011; 12:273-274.

2. May A, Schulte LH. Chronic migraine: risk factors, mechanisms and treatment. Nat Rev Neurol. 2016; 12:455-464.

3. Headache Classification Committee of the International Headache Society (IHS) The International Classification of Headache Disorders, 3rd edition. Cephalalgia. 2018; 38:1-211.

4. Lionetto L, Negro A, Palmisani S, et al. Emerging treatment for chronic migraine and refractory chronic migraine. Expert Opin Emerg Drugs. 2012; 17:393-406

5. Lu SR, Fuh JL, Chen WT. Et al. Chronic daily headache in Taipei, Taiwan: prevalence, follow-up and outcome predictors. 2001; 21:980-986.

6. Wang SJ, Fuh JL, Lu SR, et al. Chronic daily headache in Chinese elderly: Prevalence, risk factors, and biannual follow-up. Neurology. 2000; 54:314-319.

7. Schulman EA, Lake AE 3rd, Goadsby PJ. Et al. Defining refractory migraine and refractory chronic migraine: proposed criteria from the Refractory Headache Special Interest Section of the American Headache Society. 2008; 48:778-782.

8. Ramachandran, R. Yaksh, T.L. Therapeutic use of botulinum toxin in migraine: mechanisms of action. Br. J. Pharmacol. 2014; 171: 4177-4192.

9. Aurora SK, Dodick DW, Turkel CC, et al. OnabotulinumtoxinA for treatment of chronic migraine: results from the double-blind, randomized, placebo-controlled phase of the PREEMPT 1 trial. Cephalalgia. 2010; 30:793-803. 
10. Diener HC, Dodick DW, Aurora SK, et al. OnabotulinumtoxinA for treatment of chronic migraine: results from the double-blind, randomized, placebo-controlled phase of the PREEMPT 2 trial. Cephalalgia. 2010; 30:804-814.

11. Dodick DW, Turkel CC, DeGryse R, et al. OnabotulinumtoxinA for treatment of chronic migraine: pooled results from the double-blind, randomized, placebo-controlled phases of the PREEMPT clinical program. Headache. 2010; 50:921-936.

12. Sluijter ME. Pain in Europe, Barcelona. Non-thermal Radiofrequency Procedures in the Treatment Spinal Pain. 2nd Annual Congress of the European Federation of IASP Chapters; 1997; p. 326.

13. Chang MC. Efficacy of pulsed radiofrequency stimulation in patients with peripheral neuropathic pain: a narrative review. Pain Physician. 2018; 21:E225-234.

14. Sluijter ME, Cosman ER, Rittman III W, Kleef M. The effects of pulsed radiofrequency fields applied to the dorsal root ganglion. Pain Clin 1998; 11:109-118.

15. Van Zundert J, de Louw AJ, Joosten EA, et al. Pulsed and continuous radiofrequency current adjacent to the cervical dorsal root ganglion of the rat induces late cellular activity in the dorsal horn. Anesthesiology. 2005; 102:125-131.

16. Cohen SP, Peterlin BL, Fulton L, et al. Randomized, double-blind, comparative-effectiveness study comparing pulsed radiofrequency to steroid injections for occipital neuralgia or migraine with occipital nerve tenderness. 2015; 156:2585-2594.

17. Gabrhelík T, Michálek P, Adamus M. Pulsed radiofrequency therapy versus greater occipital nerve block in the management of refractory cervicogenic headache-a pilot study. Prague Med Rep. 2011; 112:279-287.

18. Vanderhoek MD, Hoang HT, Goff B. Ultrasound-guided greater occipital nerve blocks and pulsed radiofrequency ablation for diagnosis and treatment of occipital neuralgia. Anesth Pain Med. 2013; 3:256-259.

19. Martelletti P, Katsarava Z, Lampl C, et al. Refractory chronic migraine: a consensus statement on clinical definition from the European Headache Federation. $J$ Headache Pain. 2014;15:47.

20. Greher M, Moriggl B, Curatolo M, Kirchmair L, Eichenberger U. Sonographic visualization and ultrasound-guided blockade of the greater occipital nerve: a comparison of two selective techniques confirmed by anatomical dissection.Br J Anaesth. 2010;104(5):637-642.

21. Charles A. The pathophysiology of migraine: implications for clinical management. Lancet Neurol. 2018;17:174-182.

22. Dodick DW, Turkel CC, DeGryse RE, et al. OnabotulinumtoxinA for treatment of chronic migraine: pooled results from the double-blind, randomized, placebo-controlled phases of the PREEMPT clinical program. Headache. 2010;50:921-936.

23. Conway S, Delplanche C, Crowder J, Rothrock J. Botox therapy for refractory chronic migraine. Headache. 2005;45:355-357.

24. Butera $C$, Colombo $B$, Bianchi $F$, et al. Refractory chronic migraine: is drug withdrawal necessary before starting a therapy with onabotulinum toxin type A?. Neurol Sci. 2016;37:1701-1706. 
25. Palma JA, Irimia P, Fernandez-Torron $R$, et al. Clinical experience of treatment with onabotulinumtoxin A in patients with refractory migraine. Rev Neurol. 2012;54:705-711.

26. Dressler D. Clinical presentation and management of antibody-induced failure of botulinum toxin therapy. Mov Disord. 2004;19 Suppl 8:S92-S100.

27. Naumann $\mathrm{M}$, Carruthers $\mathrm{A}$, Carruthers $\mathrm{J}$, et al. Meta-analysis of neutralizing antibody conversion with onabotulinumtoxinA (BOTOX®) across multiple indications. Mov Disord. 2010;25:2211-2218.

28. Kwak S, Chang MC. Management of refractory chronic migraine using ultrasound-guided pulsed radiofrequency of greater occipital nerve: Two case reports. Medicine (Baltimore). 2018;97:e13127.

29. Li J, Yin Y, Ye L, Zuo Y. Pulsed radiofrequency of $C 2$ dorsal root ganglion under ultrasound guidance for chronic migraine: a case report. J Pain Res. 2018;11:1915-1919.

30. Palamar D, Uluduz D, Saip S, Erden G, Unalan H, Akarirmak U. Ultrasound-guided greater occipital nerve block: an efficient technique in chronic refractory migraine without aura?. Pain Physician. 2015;18:153-162.

31. Inan LE, Inan N, Karadaş Ö, et al. Greater occipital nerve blockade for the treatment of chronic migraine: a randomized, multicenter, double-blind, and placebo-controlled study. Acta Neurol Scand. 2015;132:270-277.

32. Saper JR, Dodick DW, Silberstein SD, et al. Occipital nerve stimulation for the treatment of intractable chronic migraine headache: ONSTIM feasibility study. Cephalalgia. 2011;31:271-285.

\section{Tables}




\begin{tabular}{|c|c|c|c|c|c|c|c|}
\hline № & Age & $\begin{array}{l}\text { Migraine } \\
\text { duration, } \\
\text { y }\end{array}$ & $\begin{array}{l}\text { Refractory } \\
\text { migraine } \\
\text { duration, y }\end{array}$ & $\begin{array}{l}\text { Number of } \\
\text { headache days } \\
\text { per month }\end{array}$ & $\begin{array}{l}\text { Pain } \\
\text { intensity, } \\
\text { NRS }\end{array}$ & Therapy & $\begin{array}{l}\text { Previous } \\
\text { BTA } \\
\text { injection }\end{array}$ \\
\hline 1 & 51 & 44 & 3 & 18 & 9 & $\begin{array}{l}\text { Triptane, TCA, } \\
\text { AED, MR }\end{array}$ & 2 \\
\hline 2 & 39 & 22 & 10 & 30 & 7 & $\begin{array}{l}\text { Triptane, TCA, } \\
\text { AED, AB, SNRI, } \\
\text { NSAID, SD }\end{array}$ & $\begin{array}{l}4 \\
\text { injections }\end{array}$ \\
\hline 3 & 33 & 16 & 6 & 25 & 8 & $\begin{array}{l}\text { Triptane, AED, } \\
\text { AB, SNRI, SSRI, } \\
\text { SD }\end{array}$ & $\begin{array}{l}1 \\
\text { injection }\end{array}$ \\
\hline 4 & 48 & 30 & 1 & 20 & 6 & $A E D, A B, S D$ & $\begin{array}{l}1 \\
\text { injection }\end{array}$ \\
\hline 5 & 44 & 29 & 2,5 & 22 & 8 & $\begin{array}{l}\text { Triptane, TCA, } \\
\text { AB, NSAID, } \\
\text { COMB }\end{array}$ & $\begin{array}{l}1 \\
\text { injection }\end{array}$ \\
\hline 6 & 57 & 19 & 2 & 18 & 5 & $\begin{array}{l}\text { Triptane, NSAID, } \\
\text { AED, COMB }\end{array}$ & $\begin{array}{l}1 \\
\text { injection }\end{array}$ \\
\hline
\end{tabular}

Table 1. Patient demographic and clinical characteristics. (TCA - tricyclic antidepressants, SNRI serotonin and norepinephrine reuptake inhibitor, SSRI - selective serotonine reuptake inhibitor, AED antiepileptic drugs, MR - muscle relaxant, NSAID - nonsteroidal antiinflammatory drug, AB - betaadrenoblockers, SD - sartan drugs, COMB - combined analgetics). 


\begin{tabular}{|c|c|c|c|c|}
\hline № & Age & $\begin{array}{l}\text { Previous BTA } \\
\text { injection }\end{array}$ & Therapy before & Therapy after \\
\hline \multirow[t]{3}{*}{1} & 44 & 1 injections & - Metoprolol100 mg & - NSAID \\
\hline & & & -Sumatriptan $200 \mathrm{mg}$ & -Amitriptyline $25 \mathrm{mg}$ \\
\hline & & & -Amitriptyline $100 \mathrm{mg}$ & \\
\hline \multirow[t]{5}{*}{2} & 39 & 4 injections & - Sertraline $50 \mathrm{mg} /$ Duloxetine $60 \mathrm{mg}$ & -NSAID \\
\hline & & & - Topiromate 100 mg & -Amitriptyline 100 \\
\hline & & & - Metoprolol 75 mg & $\pi$ \\
\hline & & & - Candesartan $16 \mathrm{mg}$ & \\
\hline & & & -Sumatriptan $200 \mathrm{mg}$ & \\
\hline \multirow[t]{4}{*}{3} & 33 & 1 injection & - Topiromate 200 mg & NSAID \\
\hline & & & - Candesartan $16 \mathrm{mg}$ & -Amitriptyline $50 \mathrm{mg}$ \\
\hline & & & -Sumatriptan $200 \mathrm{mg}$ & \\
\hline & & & $\begin{array}{l}\text { - Sertraline } 100 \mathrm{mg} / \text { Duloxetine } 60 \\
\text { mg }\end{array}$ & \\
\hline
\end{tabular}

Table 2. Prophylactic and abortive daily therapy changes.

\section{Figures}




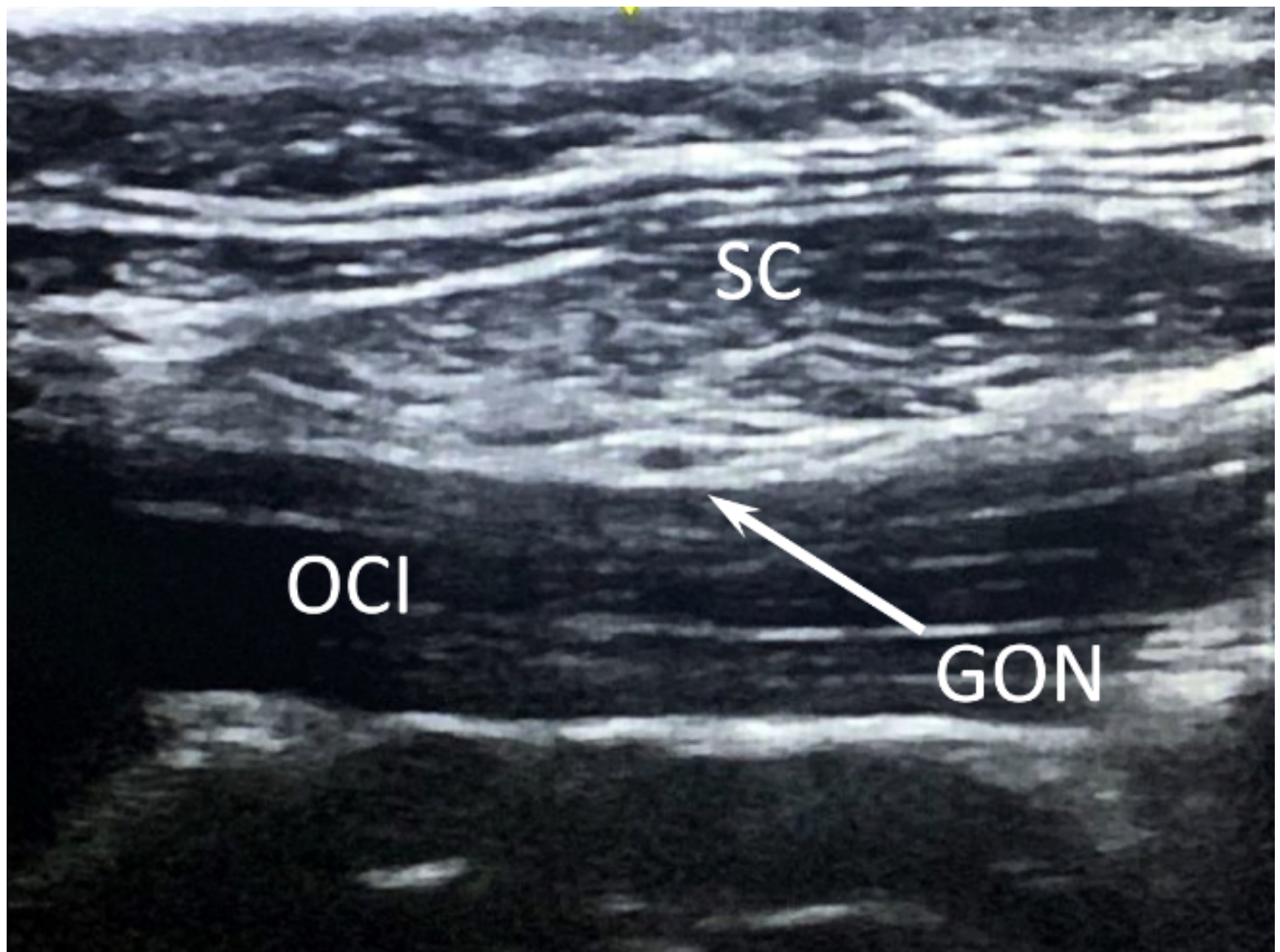

\section{Figure 1}

Transverse ultrasound image of the GON at $\mathrm{C} 2$ level. GON arrow = great occipital nerve, $\mathrm{OCl}=$ oblique capitis inferior muscle, $\mathrm{SC}=$ splenius capitis 


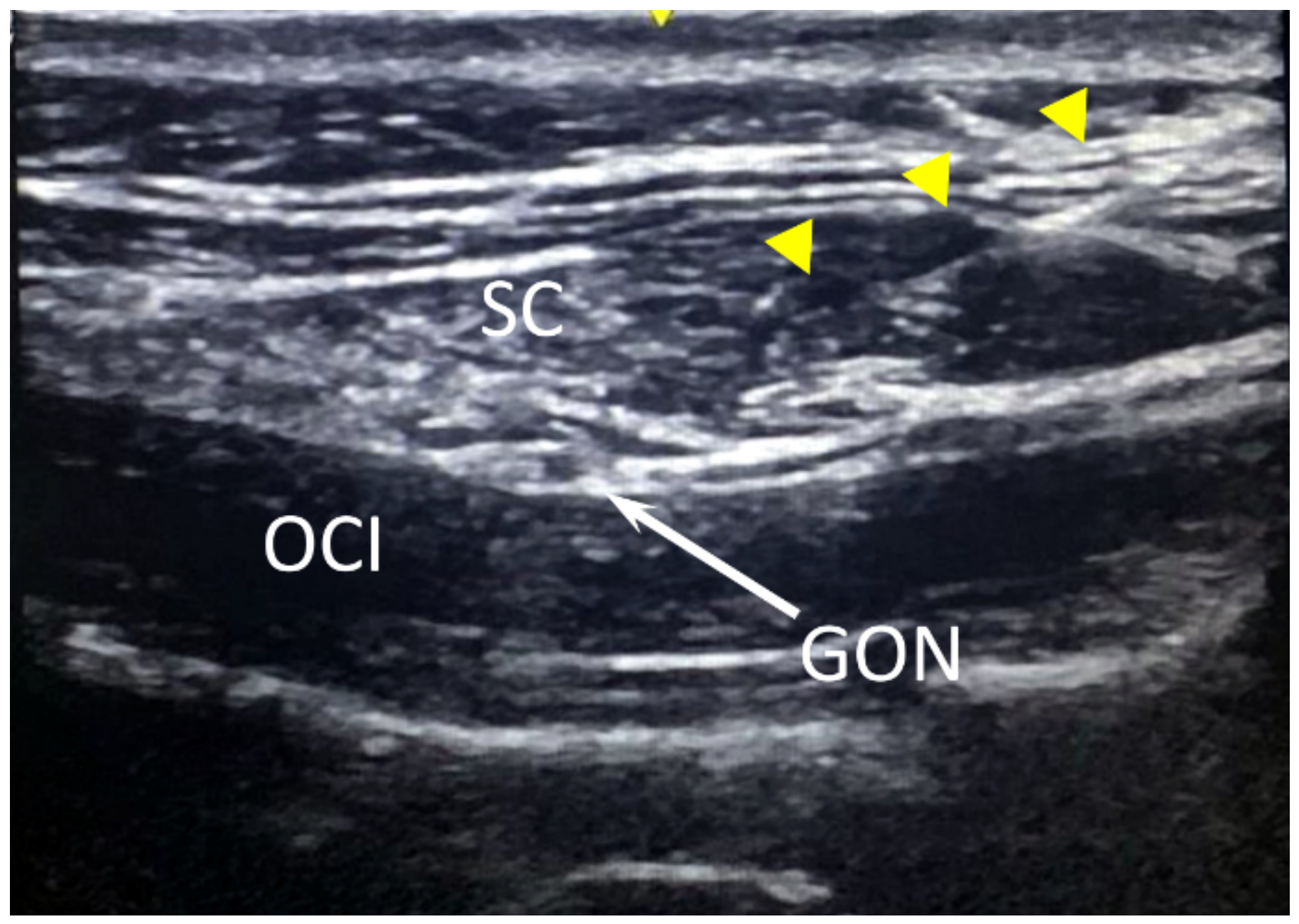

Figure 2

Canulla insertion process, transverse ultrasound image. $\mathrm{GON}$ arrow = great occipital nerve, $\mathrm{OCI}=$ oblique capitis inferior muscle, SC = splenius capitis. Arrowheads - canulla. 


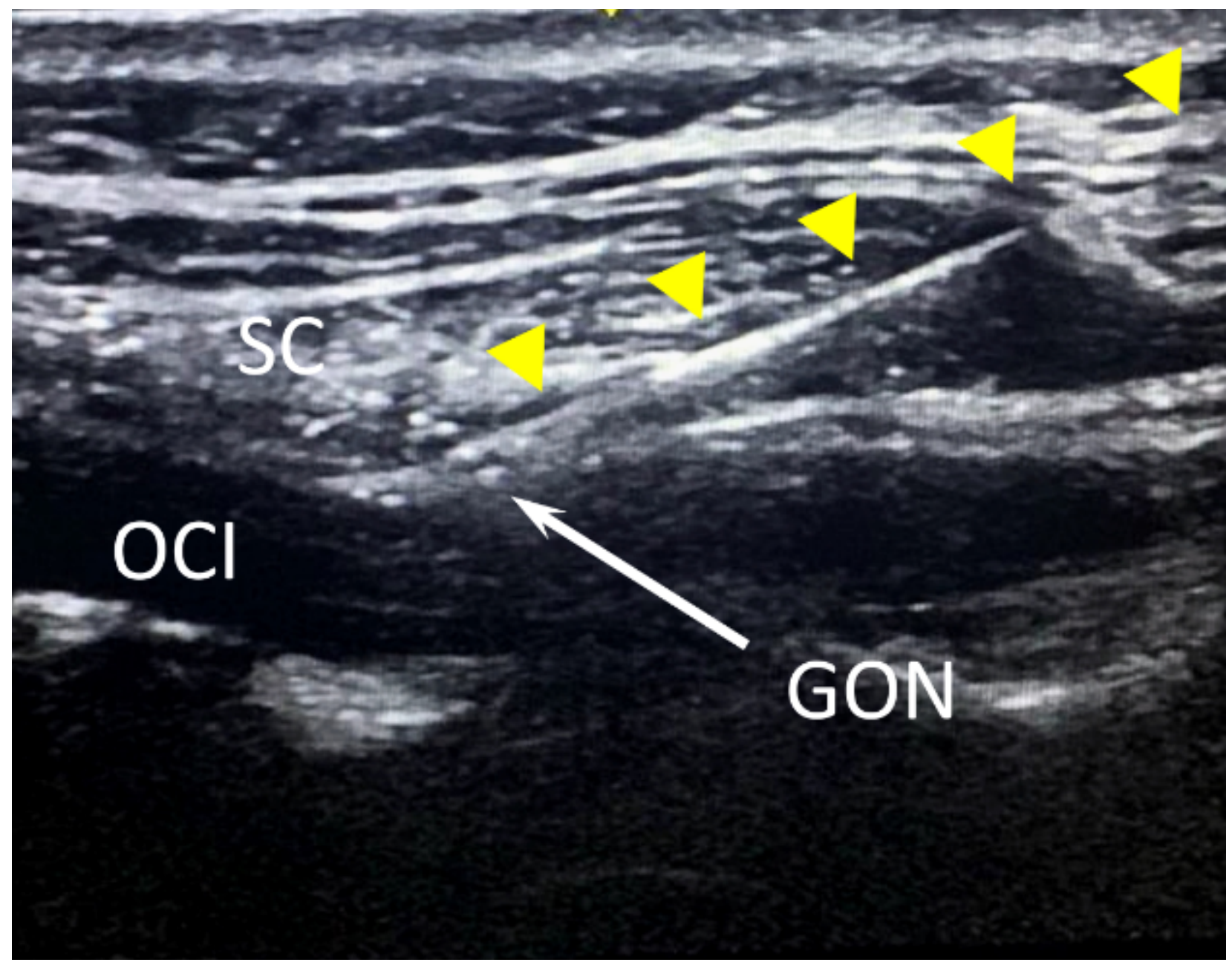

Figure 3

PRF GON process, transverse ultrasound image GON arrow = great occipital nerve, $\mathrm{OCI}=$ oblique capitis inferior muscle, $\mathrm{SC}=$ splenius capitis. Arrowheads - canulla. 


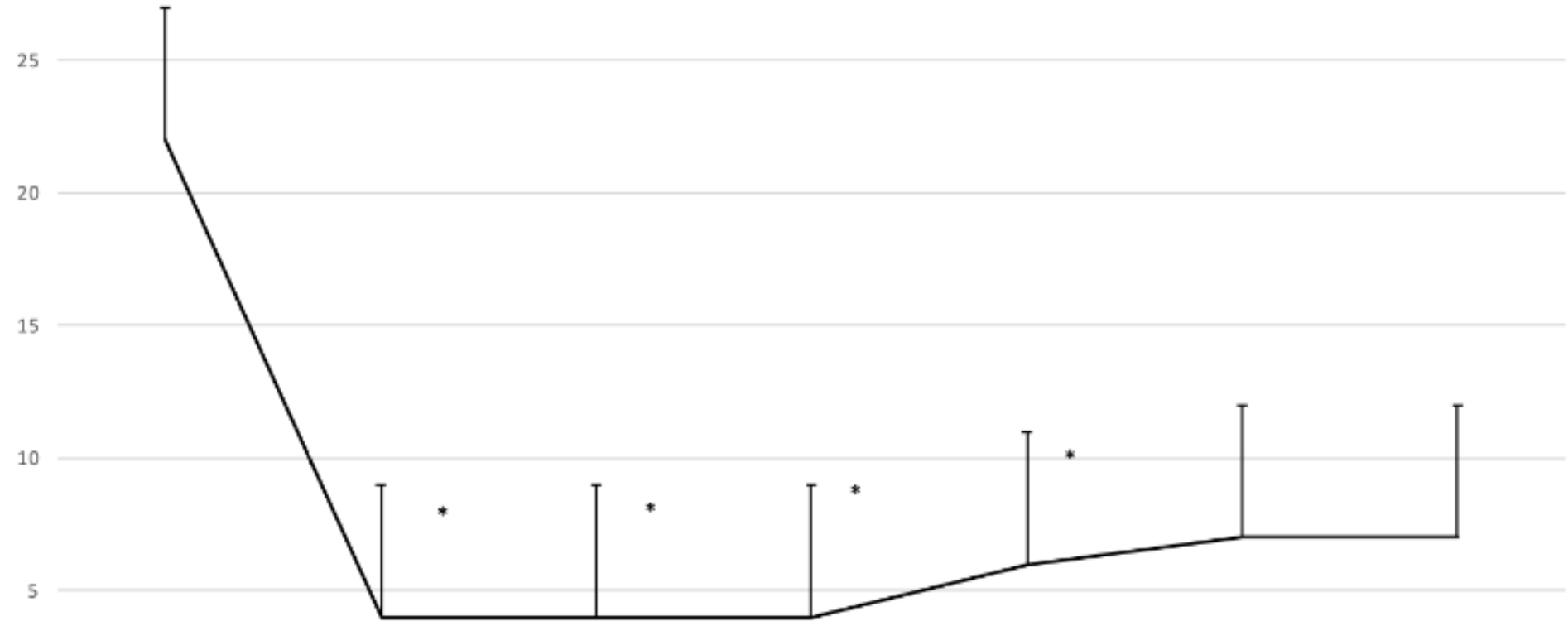

\section{Figure 4}

Number of headache days per month (mean \pm SD, * - p $₫ 0,05$ ) 
9

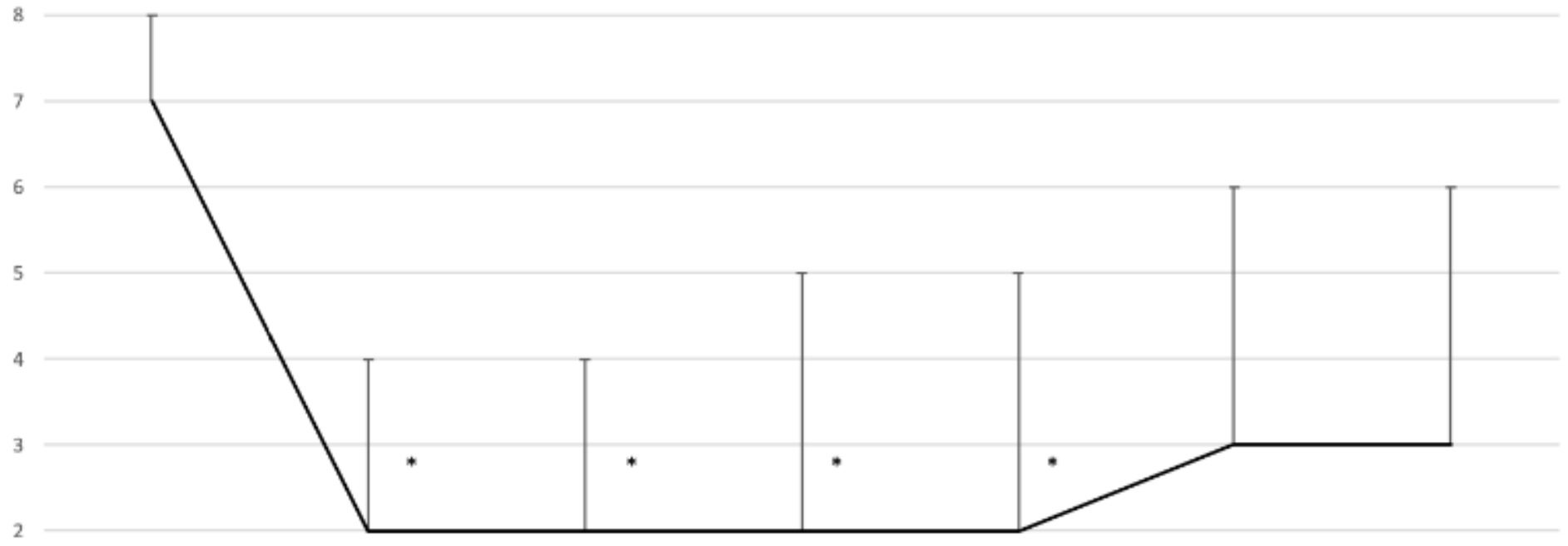

1

0

Before treatment

1 month

2 months

3 months

4 months

5 months

6 months

Figure 5

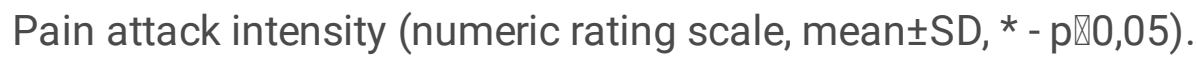

